\title{
DEMOCRACIA 4.0: UMA BREVE DISCUSSÃO SOBRE FAKE NEWS E OS LIMITES CONSTITUCIONAIS DO DIREITO FUNDAMENTAL À LIBERDADE DE EXPRESSÃO EM TEMPOS DE PANDEMIA E SEGURANÇA HUMANA
}

\section{Cláudia M. Felix de Vico Arantes da Silva ${ }^{1}$}

RESUMO: O presente trabalho apresenta temas entrelaçados: democracia digital, fake news e liberdade de expressão em tempos de pandemia. No ambiente digital, as fakes news multiplicaram-se, e, agora, tais mecanismos virtuais são utilizados para propagar falsas informações sobre o vírus e sua disseminação. A liberdade de expressão não é direito absoluto e mecanismos legais devem ser utilizados visando coibir a disseminação de notícias falsas. $\mathrm{O}$ conceito de segurança humana segundo parâmetros fixados em documentos internacionais abrange a saúde, e o uso indiscriminado do direito à liberdade de expressão, quando do compartilhamento de fake news significa uma ameaça à segurança humana.

PALAVRAS-CHAVE: cyberdemocracia, fake news, liberdade de expressão, pandemia, segurança humana.

\section{DEMOCRACY 4.0: A BRIEF DISCUSSION ON FAKE NEWS AND THE CONSTITUTIONAL LIMITS OF THE FUNDAMENTAL RIGHT TO FREEDOM OF EXPRESSION IN TIMES OF PANDEMIC AND HUMAN SECURITY}

\begin{abstract}
The present work presents intertwined themes: digital democracy, fake news and freedom of expression in times of pandemic. In the digital environment, fakes news have multiplied, and now these virtual mechanisms are used to propagate false information about the virus and its spread. Freedom of expression is not an absolute right and legal mechanisms should be used to curb the spread of false news. The concept of human security according to parameters set out in international documents covers health, and the indiscriminate use of the right to freedom of expression, when sharing fake news means a threat to human security.
\end{abstract}

KEYWORDS: cyberdemocracy, fake news, freedom of expression, pandemic, human security.

\section{INTRODUÇÃO}

\footnotetext{
$1 *$ Possui graduação em Direito - FUNDINOPI/UENP - Faculdade de Direito de Jacarezinho (1996) e Mestrado em Ciência Jurídica - FUNDINOPI/UENP - Faculdade de Direito de Jacarezinho (2011). Advogada, sócia do escritório MVS Advogados Associados, com sede em Curitiba-PR, e professora, atua principalmente nas áreas trabalhista e empresarial. É professora de Direito Constitucional, História do Direito, Estágio III e IV da FAE. É pesquisadora nas áreas de Direito Constitucional e Trabalhista, com enfoque na utilização da Jurisdição Constitucional na Efetivação de Direitos Sociais. Também leciona Direito Material do Trabalho. Integra o Colégio de Professores da Academia Brasileira de Direito Constitucional ABDConst. Desenvolve atividades nas áreas de pesquisa e extensão em Direitos Humanos e Democracia. Ganhadora do Prêmio Nacional Boas Práticas Google For Education- categoria - Ensino Superior, com a participação do projeto de Extensão Law Games 2019. É pesquisadora pela Clínica Direito do Trabalho, projeto de pesquisa e extensão vinculado ao Curso de Direito e ao Programa de Pós-Graduação em Direito da Universidade Federal do Paraná e do GPCertos - UENP. Email: draclaudiadevico@ymail.com.
} 
A partir do surgimento e expansão do uso de tecnologias digitais, redes sociais e aplicativos de comunicação instantânea, um novo viés da democracia tem sido objeto de pesquisa pelos cientistas políticos e sociólogos: a democracia digital, democracia 4.0 ou ciberdemocracia. A expressão cunhada por Gomes (2007, p.1) está relacionada ao uso das redes sociais e outros mecanismos de compartilhamento de informação como instrumentos aptos a possibilitar um novo canal de debate e até mesmo o exercício de uma nova espécie de cidadania.

Embora a internet tenha surgido como sinal de esperança para o aumento do compartilhamento e acesso às mais variedades temáticas de conhecimento pela maioria da população, tem também sido utilizada para a propagação de falsas informações, as chamadas fakes news que surgiram primeiramente nos processos eleitorais, mas também tem sido propagadas em toda ordem de discussão, agora, inclusive no que se refere às notícias sobre a pandemia, vírus, utilização de medicamentos, vacina etc.

Tal fenômeno, em tempos de pandemia tem colocado em risco a vida das pessoas, que se deparam desde receitas caseiras para a cura do vírus até mesmo com campanhas negacionistas sobre a própria existência do vírus e eficiência das vacinas.

Esta breve pesquisa propõe afirmar que o direito fundamental à liberdade de expressão tem limites, e que a sua fruição de forma desmedida e irresponsável em tempos de pandemia coloca em risco outro direito fundamental: a saúde e a integridade das pessoas, senão a própria vida humana.

Também, em suma síntese afirmar-se-á que a propagação de tais notícias atenta contra a segurança humana das pessoas, a partir do conceito que tem sido desenvolvido no âmbito da Organização das Nações Unidas e estudiosos do assunto.

A proposta tem por objetivo ainda considerar como pano de fundo a chamada democracia digital, já que tal fenômeno possibilita que qualquer pessoa com acesso à internet participe do debate democrático por meio das redes sociais, opinando inclusive sobre as mais variadas matérias e sem qualquer conhecimento sobre o assunto. Fica a pergunta, para ser respondida, talvez em outra pesquisa: isto é democracia?

\section{EM TEMPOS DE DEMOCRACIA 4.0 OU DEMOCRACIA DIGITAL - A INFLUÊNCIA DAS REDES SOCIAIS}


Não é de hoje, que democracia é considerada como um conceito em construção, cujos mecanismos de funcionamento ainda estão sendo consolidados e aprimorados. Desde a democracia direta grega até o desenvolvimento da chamada democracia representativa e participativa, vários desafios têm se apresentado para o aprimoramento do exercício do poder pelos representantes eleitos pelo povo. O fato é que a democracia moderna está em crise!

Construir e consolidar democracias não constitui tarefa fácil, e no caso brasileiro, a dificuldade se intensifica ante a desigualdade social existente, afinal a chamada Constituição Cidadã não obteve sucesso em universalizar direitos; tem-se avanços, com certeza, mas apenas alguns grupos sociais foram contemplados.

Mas, em meio à crise democrática, nos últimos anos tal regime de governo assumiu um novo modus operandi, qual seja: a chamada democracia digital ou midiática, também chamada de ciberdemocracia, democracia virtual e democracia eletrônica (GOMES, 2007, p.1). Aqui também se utilizará a expressão democracia 4.0, numa referência às eras de desenvolvimento da internet que se dividem em 1.0, 2.0, 3.0 e 4.0 ${ }^{2}$, conforme o estágio de desenvolvimento e ferramentas tecnológicas utilizadas.

A par daqueles que já vem conceituando o fenômeno, nesta breve digressão a expressão democracia digital será considerada como um novo mecanismo de instrumentalização do jogo democrático, uma vez que permite, por meio da utilização de ferramentas digitais a ampliação do debate, visto que qualquer pessoa com acesso a celular pode acessar as redes sociais e emitir uma opinião sobre qualquer assunto, até mesmo sobre saúde, eficácia de remédios e confiabilidade de vacinas!

As redes sociais possibilitaram que um único usuário tenha condições de viralizar uma informação para milhares de pessoas e de forma muito rápida, em poucos segundos; aliás, os custos da participação política despencaram, visto que não está mais vinculado ao gasto com a impressão de um panfleto ou o alto preço de alguns minutos numa estação de rádio ou de televisão.

Robert Dahl, em sua obra Poliarquia (1960) discorre sobre os pressupostos para o funcionamento das democracias, e entre eles elenca a proteção ampla das liberdades individuais, incluindo a liberdade de expressão.

\footnotetext{
${ }^{2}$ Desde o surgimento da internet, a word wide web passou por várias fases, que se diferenciam conforme as tecnologias e ferramentas desenvolvidas e disponibilizadas; e a partir de 2019, inicia-se a chamada era da web 4.0, caracterizada pelo uso massivo da inteligência artificial.
} 
E, também Norberto Bobbio (2004, p. 22), afirma que: “(...) por regime democrático entende-se primariamente um conjunto de regras de procedimento para a formação de decisões coletivas, em que está prevista e facilitada a participação mais ampla possível dos interessados".

E, Wilson Gomes (2007, p. 2) complementa:

Sabemos que a ideia de democracia é, depois, elaborada diferentemente em diversas escolas e correntes de teoria da democracia e materializada em instituições e procedimentos por diferentes concepções socialmente compartilhadas ao longo do tempo. A expressão "modelos de democracia" remete, naturalmente, a David Held 1987), mas aqui é usada para designar e caracterizar as teorias quando elas se concretizam, ainda que apenas como projetos, num corpo de procedimentos e de instituições. Assim, por exemplo, a teoria rousseauniana da democracia se materializa historicamente tanto em modelos de democracia direta, quanto nos modelos republicano cívico e comunitarista. As "ênfases" são menos que "modelos", são características destacadas por um ou vários modelos dentre as várias dimensões da ideia de democracia. Um bom exemplo de ênfase é dado pela ideia de participação popular ou civil, que pode ser compartilhada por modelos muito diferentes como, por exemplo, os partidários da "democracia forte" (Pateman, Barber), os deliberacionistas (vide Mutz 2006), os comunitaristas tocquevilleanos (Putnam 2000) e a democracia radical (Mouffe).

Convém destacar que não se pretende aqui discutir a origem e abordar a polêmica sobre o conceito de democracia, a ênfase ora destacada diz respeito a possíveis aspectos do conceito de democracia 4.0 (ou democracia digital), cujo debate já é considerado amplo e não sistematizado. Há àqueles teóricos segundo os quais a democracia digital implica num liberalismo digital, com preponderância ao exercício dos direitos individuais e há, outros que, chamados de participacionistas digitais privilegiam instrumentos de deliberação pública e ferramentas de participação popular.

Parte-se da premissa que o exercício democrático não se limita ao exercício do direito ao voto, mas também estará sendo efetivado toda vez que a sociedade civil se utiliza da web para sua autorrepresentação social e política e também para discussões de temas que lhe dizem respeito; isto é democracia 4.0, e também o são, a utilização pelos partidos políticos dos recursos digitais para divulgação de suas ideologias, bem como, sites do governo quanto publicam informações sobre sua gestão, entre outros.

Enfim, o surgimento das tecnologias digitais, entre elas a disseminação do uso do celular, veio carregado de esperança e o acesso `internet surgiu como promessa, pois afinal possibilitaria o acesso de milhares de pessoas que antes era invisíveis à grande sociedade; ocorre que tal mecanismo empoderou também os mercadores das falsas notícias, que por meio 
de apenas um clique conseguem adeptos para popularizar informações desprovidas de qualquer fundamento de verdade.

\begin{abstract}
A atitude intelectual segundo a qual a internet é uma promessa foi dominante pelo menos até a virada do século (Rheingold, 1993). De fato, a internet parecia a terra prometida da participação tanto pelo que impedia quanto pelo que proporcionava. De fato, ela impedia ou, ao menos, reduzia consideravelmente a importância de circunstâncias sociais que atrofiam a autonomia da comunidade dos cidadãos. Os intermediários e guardadores de portões, que tradicionalmente se põem entre a sociedade civil e o Estado (partidos políticos, burocracia, corporações, indústria da informação) e entre os diversos componentes da sociedade civil mesma (a comunicação de massa), podem finalmente ser evitados na era da comunicação em rede. O cidadão pode se relacionar diretamente ao Estado ou ao sistema político, sem mediação dos meios de massa ou das instituições intermediárias; os membros da comunidade política podem agora, na alternância entre livre emissão e livre recepção, produzir uma comunicação sobre as coisas do seu próprio interesse, a prescindir do Estado, do sistema político ou dos meios de massa. A internet, portanto, está em condições de prover poderosos instrumentos self-service (ou autônomos, isto é, produzidos pela sociedade civil para o consumo dos próprios cidadãos) de formação da opinião e da vontade políticas e fantásticas oportunidades de participação e engajamento por parte da sociedade civil. Uma participação que se deveria materializar, alternativamente e a depender da ênfase participacionista adotada, como influência civil sobre o sistema político, como colaboração civil na produção da decisão política e administrativa, ou, enfim, como alguma forma de autogoverno civil ou democracia digital direta, em que a esfera civil substitui o próprio sistema político na produção da decisão política. (GOMES, 2007, p. 4).
\end{abstract}

Mas, afinal, quando e como a internet pode ser colocada como serviço para a democracia? Bem, como destacado anteriormente essa resposta depende de uma série de fatores, até mesmo de posições ideológicas-partidárias, fatores de desigualdade social, participação política, níveis educacionais da população, acesso à internet, entre outros. A discussão perpassa ainda a possibilidade de participação da população na votação de leis e sua influência na criação de políticas públicas que melhorem sua condição de vida.

E o papel do Estado? Viabilizar mecanismos de transparência de informações por exemplo, e ainda, proporcionar meios para que as populações de baixa renda acessem tecnologias digitais? E investir em educação para que a sociedade como um todo, ou, em grande número possa compreender e saber utilizar tais ferramentas tecnológicas? Otimizar o engajamento político e uma cultura de participação popular? Tais perguntas ainda deverão ser respondidas.

\title{
3. AS FAKE NEWS E A PANDEMIA: FATORES QUE CONTRIBUEM PARA SUA DISSEMINAÇÃO
}


A expressão fake news se tornou corriqueira nos últimos tempos, e ganhou peculiar notoriedade nas eleições presidenciais dos Estados Unidos da América, no ano de 2016, quando supostamente foram utilizadas para auxiliar na chegada ao poder de Donald Trump.

E, conforme Mounk, a eleição de Trump foi a manifestação mais aparente de crise da democracia, afinal, o povo americano elegeu um presidente que despreza abertamente as normas constitucionais. Tal fenômeno não é um caso isolado. Mounk cita casos como o da Rússia, Polônia e Hungria (MOUNK, 2019, p.16).

Da tradução do inglês para a língua portuguesa, significa "notícias falsas" e expressa a utilização acerca da veiculação de falsas notícias cujo intuito pode ser disseminar conteúdos sensacionalistas, ou até mesmo, propagar ódio e discriminação.

No Brasil, a situação acerca da disseminação de fake news também se agravou e, no ano de 2019, deu ensejo à abertura de investigação via Comissão Parlamentar de Inquérito no âmbito do Senado Federal. A referida comissão iniciada por meio do requerimento de n. 11/2019 investiga os ataques cibernéticos que atentam contra a democracia e o debate público; a utilização de perfis falsos para influenciar os resultados das eleições 2018; a prática de cyberbullying sobre os usuários mais vulneráveis da rede de computadores, bem como sobre agentes públicos; e o aliciamento e orientação de crianças para o cometimento de crimes de ódio e suicídio.

No referido requerimento, assim consta no item que justifica o pedido:

\begin{abstract}
Desde a volta da população às ruas, por ocasião das manifestações de junho de 2013, quando o aumento das tarifas de ônibus fez irromper uma onda de protestos por todo o Brasil, podemos assistir à transformação das redes sociais em um reconhecido espaço de expressão da democracia, uma vez terem estas assumido um protagonismo como instrumento de mobilização e de difusão de informações. No entanto, como reflexo do que acontecia nas ruas, as redes foram inundadas por velhas estratégias políticas de difamação e de manipulação de debates públicos, razão pela qual têm se tornado um verdadeiro campo de batalha. Campanhas de ódio, assédios, exposição da intimidade alheia e até tentativa de homicídio usando a Internet como meio de aproximação são riscos enfrentados com frequência cada vez maior pelos usuários. A Internet e as redes sociais criaram um espaço infinito para a livre circulação de ideias e opiniões, fato que culminou na instalação de verdadeiros tribunais instantâneos que elevam ou enterram as reputações tanto de agentes públicos quanto de cidadãos comuns, sem a menor piedade e responsabilização. $\mathrm{O}$ desenvolvimento desse ambiente fértil e hostil para a disseminação opiniões viabilizou, ainda, a automatização de ferramentas de publicação, resultando no surgimento e na propagação de robôs - contas controladas por softwares que se fazem passar por seres humanos, os quais já dominam parte das redes sociais e participam ativamente das discussões em momentos políticos de grande repercussão. ${ }^{3}$
\end{abstract}

\footnotetext{
${ }^{3}$ Trecho do Requerimento de instituição de CPMI n. 11/2019.
} 
Em território brasileiro, quanto aos fatores que tem estimulado sua disseminação se encontram com certeza, o baixo nível de escolaridade, a falta de uma cultura política devidamente fundamentada do ponto de vista teórico e científico e talvez a busca incessante por popularidade.

Percebe-se que com o início da pandemia, a situação se agravou ainda mais, afinal, as fake news agora colocam em risco a saúde e a integridade das pessoas, se não sua própria vida. De certo modo, pode-se afirmar que a fake news também é vírus que contaminou grande parte da população.

O assunto é tão preocupante que até a Organização Mundial da Saúde (OMS) usou o termo infodemia para se referir à prática de divulgar notícias falsas ou informações incorretas relacionadas à pandemia, uma vez que, a desinformação implica em colocar em risco a saúde e a integridade de muitas pessoas. ${ }^{4}$

Segundo dados publicados pela Organização de Saúde Panamericana ${ }^{5}$, em 2020, 361 milhões de vídeos foram carregados no YouTube nos últimos 30 dias com a classificação “COVID-19" e "COVID 19", e cerca de 19.200 artigos foram publicados no Google Scholar desde o início da pandemia. No mês de março, cerca de 550 milhões de tuítes continham os termos coronavírus, corona vírus, covid19, covid-19, covid_19 ou pandemic [pandemia].

De acordo com dados de uma pesquisa realizada pela ESET ${ }^{6}$ na América Latina em maio de 2020, mais de $70 \%$ dos participantes garantiram que receberam ou tiveram algum tipo de contato com notícias falsas relacionadas ao Covid-19 durante a pandemia principalmente através de redes sociais $(72 \%)$, mas também via WhatsApp (51\%) e em sites de notícias não confiáveis $(36 \%)$.

O impacto e risco desse fenômeno galgou proporções grandiosas, o que levou algumas redes sociais, como Facebook, Google, LinkedIn, Microsoft, Twitter, Reddit e

\footnotetext{
${ }^{4}$ Conforme declarado pela OMS, o surto de COVID-19 e a resposta a ele têm sido acompanhados por uma enorme infodemia: um excesso de informações, algumas precisas e outras não, que tornam difícil encontrar fontes idôneas e orientações confiáveis quando se precisa. A palavra infodemia se refere a um grande aumento no volume de informações associadas a um assunto específico, que podem se multiplicar exponencialmente em pouco tempo devido a um evento específico, como a pandemia atual. Nessa situação, surgem rumores e desinformação, além da manipulação de informações com intenção duvidosa. Na era da informação, esse fenômeno é amplificado pelas redes sociais e se alastra mais rapidamente, como um vírus. (Zarocostas, J. (2020). How to fight an infodemic. The Lancet, 395(10225), 676). Dados inseridos no folheto Informativo da Organização Panamericana de Saúde. Disponível em https://iris.paho.org/bitstream/handle/10665.2/52054/Factsheet-Infodemic_por.pdf?sequence=14. Acesso em: 8 abr. 2020.

5 Dados inseridos no folheto Informativo da Organização Panamericana de Saúde. Disponível em https://iris.paho.org/bitstream/handle/10665.2/52054/Factsheet-Infodemic_por.pdf?sequence=14. Acesso em: 8 abr. 2020.

${ }^{6}$ A ESET é uma companhia de segurança da informação sediada na Bratislava, Eslováquia. Foi fundada em 1992 a partir da fusão de duas companhias privadas, desenvolveu seu produto mais famoso, o ESET NOD32, software antivírus.
} 
YouTube, unirem forças na luta contra a desinformação e os golpes que giram em torno da pandemia, alterando as regras de moderação de conteúdo, como no caso do Twitter, quanto àquelas mensagens que incitavam as pessoas a agir contra as recomendações oficiais ${ }^{7}$.

Destaca-se ainda, que foi criado um canal do Ministério da Saúde, em 2018. Por meio dele, é possível enviar mensagens com o conteúdo recebido ao número disponibilizado pelo órgão, que irá verificar se a informação é verdadeira ou não. Procedimentos como esses já contribuem para reduzir significativamente a disseminação de fake news.

\section{DEMOCRACIA DIGITAL, LIBERDADE DE EXPRESSÃO E SEGURANÇA HUMANA EM TEMPOS DE PANDEMIA}

Primeiramente, convém ressaltar que para uma análise mais confiável e até mesmo interdisciplinar do processo de elaboração da Constituição de 1988 é necessário considerar seu contexto histórico. Ora, a elaboração da constituição fora imediatamente posterior a regimes ditatoriais (por último, um regime militar) e esse é um dos motivos pelos quais o constituinte originário não hesitou em incluir na Constituição de 1988, um extenso rol de direitos e garantias individuais (no artigo $5^{\circ}$ ), como também não se pode excluir outros porventura esparsos em seu texto ou em tratados internacionais, conforme artigo 5o, § 2o da Constituição da República Federativa do Brasil.

É pacífico na doutrina e na jurisprudência que existem ainda outros direitos individuais e coletivos fundamentais fora do referido catálogo, como os direitos sociais, o direito a um meio ambiente sustentável, o direito à cultura, e outros, e, até mesmo, fora da Constituição, mas que compõe o chamado bloco de constitucionalidade, como a Convenção sobre os Direitos das Pessoas com Deficiência, aprovada de acordo com o procedimento do artigo 5o, § 3o, CF e incorporada, portanto, com força de Emenda Constitucional.

Diante desse cenário histórico, o constituinte conferiu, em virtude do cenário de censura e de ausência de liberdades vivido no período anterior e recente, uma proteção robusta às liberdades de expressão, de informação e de imprensa.

A liberdade de expressão vem consagrada nos artigos 5o, incisos IV e IX, e 220, caput da Constituição Federal, e, pode assim ser definida:

\footnotetext{
${ }^{7}$ Notícia disponível em: https://www.uol.com.br/tilt/noticias/bloomberg/2020/03/17/gigantes-da-tecnologia-se-unem-contrafake-news-do-coronavirus.htm. Acesso em: 13 abr. 2021.
} 
Por meio dela, busca-se garantir um espaço livre e amplo de circulação de ideias, com o objetivo de aquecer o debate público com diferentes ideias e pontos de vista, mantendo o pluralismo, refletindo-o no debate e garantindo a diversidade de opiniões, de modo que cada pessoa se informe - aqui há uma simbiose entre as três liberdades - e, no auge de sua autonomia individual, adote as posições políticas, filosóficas e pessoais que julgue ser as melhores para a sociedade, fazendo também suas próprias escolhas pessoais. Essa seria a dimensão instrumental da liberdade de expressão, já que ela seria o instrumento para o melhor exercício da democracia plena, garantindo, assim, o livre mercado de ideias e, consequentemente, a autodeterminação democrática. Outro aspecto relacionado à dimensão instrumental diz respeito ao fato de que, pela liberdade de expressão - e também pelas outras duas liberdades-, pode-se exercer o controle do governo e do exercício do poder. Portanto, a liberdade de expressão garante a acomodação de interesses da sociedade e de cada cidadão, sendo fundamental para uma transformação pacífica da sociedade, além da busca pela verdade (LOPES apud Machado, 2015, p. 105, grifo nosso).

Assim, pode-se aferir que o exercício de tal direito fundamental está intrinsicamente ligado ao próprio exercício da democracia. Os direitos fundamentais, entre eles a liberdade de expressão constitui a própria essência do Estado Democrático de Direito. Mas, qual será o limite do direito fundamental à liberdade de expressão? É imprescindível distinguir quando o exercício regular de um direito se torna abusivo ou ofensivo e, portanto, pode lesar outras garantias e direitos fundamentais pertencentes a outros sujeitos.

O exercício de tal direito, além de constituir-se na instrumentalização da própria democracia, também está ligado a uma necessidade humana, a de se manifestar e se expressar. E, com o advento da internet, aliado à utilização do celular, foi possível viabilizar um notável estímulo e democratização no processo de difusão de ideias, opiniões e pensamentos. Não há como negar que a internet ampliou as oportunidades de participação na esfera pública.

E assim, qualquer cidadão com acesso à internet e ao celular ${ }^{8}$, pode manifestar sua opinião e compartilhar ideias, e sobre qualquer assunto, vive-se a era dos pseudoespecialistas, todos julgam-se entendedores sobre tudo e, legítimos influenciadores digitais; lamentavelmente o que se vê é que não há a mínima preocupação com a veracidade ou fundamentação científica das informações compartilhadas e opiniões proferidas. Ora, todos se intitulam, por exemplo, no direito de proferir opiniões sobre o conteúdo e efetividade da

\footnotetext{
${ }^{8} \mathrm{O}$ percentual de domicílios que utilizavam a Internet subiu de 74,9\% para 79,1\%, de 2017 para 2018 . O rendimento médio per capita daqueles em que havia utilização da Internet era quase o dobro do rendimento dos que não utilizavam a rede. $\mathrm{O}$ equipamento mais usado para acessar a Internet foi o celular, encontrado em 99,2\% dos domicílios com serviço. O segundo foi o microcomputador, que, no entanto, só era usado em $48,1 \%$ desses lares. Já o acesso pela televisão subiu de $16,1 \%$ para 23,3\% dos domicílios com internet, de 2017 para 2018. Essas são algumas informações da PNAD Contínua do IBGE que, no quarto trimestre de 2018, pesquisou o acesso dos domicílios brasileiros à Tecnologia da Informação e Comunicação (TIC). Disponível em: https://agenciadenoticias.ibge.gov.br/agencia-sala-de-imprensa/2013-agencia-de-noticias/releases/27515pnad-continua-tic-2018-internet-chega-a-79-1-dos-domicilios-do-pais. Acesso em: 9 jun 2020.
} 
Constituição e o papel do Supremo Tribunal Federal, por exemplo. E mais grave ainda, agora em tempos de pandemia mundial, muitos usuários (que não são médicos, cientistas ou profissionais de saúde) opinam até mesmo sobre o uso de determinados medicamentos (leiase cloroquina e ivermectina). Além disso, e lamentavelmente, as redes sociais servem também como canais de discurso de incitação ao ódio, discriminação, confusão de conceitos, propagação de desavenças e por incrível que pareça, até mesmo, negação de fatos históricos. Infelizmente, o debate on-line não garante uma discussão pública "justa, representativa, efetiva e igualitária" (GOMES, 2005, p.8),

Neste tão breve estudo, não há condições de analisar temas tão profundos, mas ao que parece, o direito ao exercício do direito fundamental à liberdade de expressão não é absoluto e, portanto, tem limites. Direito à liberdade de expressão não é direito à ofensa ou à mentira! O exercício do direito à liberdade de expressão não pode implicar em danos à saúde da população.

As primeiras limitações ao exercício de tal direito dizem respeito às condutas tipificadas como crime e considerando-se os crimes mais cometidos no ambiente virtual, temse os seguintes: i) Ameaça (art. 147) quando alguém comunica outra pessoa a intenção de lhe causar algum mal injusto e grave; ii) Calúnia (art. 138), que significa imputar a alguém crime, sabendo que o mesmo é inocente; iii) Difamação (art. 139), atribuir uma conduta ofensiva a reputação de alguém e, iv) Injúria (art. 140), que corresponde ofender a dignidade ou decoro de alguém por qualquer meio, todos previstos no Código Penal, que tem como pena, multa e detenção.

Mas, são diversos os incisos do artigo $5^{\circ}$ da Constituição Federal de 1988 que discorrem acerca da liberdade de expressão. Assim, o inciso IV reza que "é livre a manifestação do pensamento, sendo vedado o anonimato", e seguido pelo inciso V, que prevê “o direito de resposta, proporcional ao agravo, além da indenização por dano material, moral ou à imagem". O inciso VIII do mesmo artigo fixa que "ninguém será privado de direitos por motivo de crença religiosa ou de convicção filosófica ou política", salvo se invocar tais crenças para ser dispensado de "obrigação legal a todos imposta e recusar-se a cumprir prestação alternativa, fixada em lei”. O inciso IX, estabelece que "é livre a expressão da atividade intelectual, artística, científica e de comunicação, independentemente de censura ou licença". O inciso X do mesmo artigo estabelece que "são invioláveis a intimidade, a vida 
privada, a honra e a imagem das pessoas, assegurado o direito a indenização pelo dano material ou moral decorrente de sua violação.

\begin{abstract}
Ainda que indiretamente, também é possível encontrar vínculos com a liberdade de expressão no inciso XIV, pelo qual "é assegurado a todos o acesso à informação e resguardado o sigilo da fonte, quando necessário ao exercício profissional". Assim, quando a liberdade de expressão seja utilizada na modalidade de exteriorização de fatos (em oposição a opiniões) ela assumirá uma de suas funções instrumentais, resguardando o direito fundamental alheio de conhecer os eventos relevantes da vida pública. Tais enunciados, em conjunto, podem ser agregados sob um rótulo de regime jurídico da liberdade de expressão individual ("comunicação um para um"). $\mathrm{O}$ direito fundamental de expressar pensamentos, todavia, não decorre somente do artigo $5^{\circ}$ da Constituição. Além da regra de imunidade tributária do artigo 150, VI, "d", que protege da incidência de impostos os "livros, jornais, periódicos e o papel destinado a sua impressão", há também uma série de enunciados constitucionais relevantes para o tema que se localizam no Título VIII do texto constitucional. Tal título versa sobre a "Ordem Social", a qual, como define o artigo 193 da Constituição, "...tem como base o primado do trabalho, e como objetivo o bem-estar e a justiça sociais” ( BRASIL JR, COLNAGO, 2012, p.6).
\end{abstract}

Ainda, COLNAGO; BRASIL JR (2012, p. 6) afirmam que "o Capítulo V do Título VIII aborda justamente a "Comunicação social", estabelecendo o regime jurídico constitucional da transmissão massiva de informação, notadamente através dos veículos tradicionais como jornais e redes de rádio e de televisão". Trata-se, segundo os autores referidos "de um regime jurídico de uma "liberdade de expressão coletiva" (comunicação "um para muitos").

O artigo 220, no caput reza que "a manifestação do pensamento, a criação, a expressão e a informação, sob qualquer forma, processo ou veículo não sofrerão qualquer restrição, observado o disposto nesta Constituição". "Tal regramento contém ainda seis parágrafos e no parágrafo segundo é reforçada a ideologia libertária constitucional ao proclamar ser "...vedada toda e qualquer censura de natureza política, ideológica e artística" (COLNAGO, BRASIL JR, 2012, p.6).

O Supremo Tribunal Federal tem estabelecido alguns limites ao exercício do direito à liberdade de expressão de forma instrumental, na análise caso a caso. Segundo alguns parâmetros extraídos de decisões do Supremo Tribunal Federal sobre o exercício do direito à liberdade de expressão (HC 82.424, RE 511.961 e ADPF 130) tem-se que tal direito não protege ilícitos penais, bem como não deve incentivar a intolerância racial e a violência, por representar uma violação da igualdade. Ainda em decisão recentíssima proferida no âmbito da análise do direito ao esquecimento (RE 1010606/RJ), o ministro Dias Toffoli destacou que o 
Supremo Tribunal Federal tem construído jurisprudência consistente em defesa da liberdade de expressão, que deve ser exercida em harmonia com os demais direitos e valores constitucionais, de modo a não alimentar o ódio, a intolerância e a desinformação. Na decisão referida destaca-se que:

\begin{abstract}
O Supremo Tribunal Federal tem construído uma jurisprudência consistente em defesa da liberdade de expressão: declarou a inconstitucionalidade da antiga lei de imprensa, por ela possuir preceitos tendentes a restringir a liberdade de expressão de diversas formas (ADPF $\mathrm{n}^{\circ}$ 130, DJe de 6/11/2009); afirmou a constitucionalidade das manifestações em prol da legalização da maconha, tendo em vista o direito de reunião e o direito à livre expressão de pensamento (ADPF n 187 , DJe de 29/5/14); dispensou diploma para o exercício da profissão de jornalista, por força da estreita vinculação entre essa atividade e o pleno exercício das liberdades de expressão e de informação ( $\mathrm{RE} \mathrm{n}^{\circ}$ 511.961, DJe de 13/11/09); determinou, em ação de minha relatoria, que a classificação indicativa das diversões públicas e dos programas de rádio e $\mathrm{TV}$, de competência da União, tenha natureza meramente indicativa, não podendo ser confundida com licença prévia (ADI n ${ }^{\circ} 2.404$, DJe de 1\%/8/17); declarou inexigível autorização de pessoa biografada relativamente a obras biográficas literárias ou audiovisuais, sendo também desnecessária autorização de pessoas retratadas como coadjuvantes -ou de seus familiares, em caso de pessoas falecidas ou ausentes - (ADI ${ }^{\circ} 4.815$, DJe de 1\%/2/16)- para citar apenas alguns casos. (STF, 2021, online)
\end{abstract}

A questão que vem à tona é a seguinte: como e quando estabelecer limites ao exercício do direito à liberdade de expressão em tempos de pandemia, uma vez que a utilização abusiva deste direito tem colocado em risco a vida e a integridade das pessoas? Considerando-se ainda que tal situação foi agravada pelo uso massivo das tecnologias digitais em tempos de democracia 4.0.

E o Supremo Tribunal Federal mostra um caminho a seguir-se:

E em que situações se identificaria esse perigo? A meu ver, a manifestação do pensamento, por mais relevante que inegavelmente seja, não deve respaldar a alimentação do ódio, da intolerância e da desinformação. Essas situações representam o exercício abusivo desse direito, por atentarem sobretudo contra o princípio democrático, que compreende o "equilíbrio dinâmico" entre as opiniões contrárias, o pluralismo, o respeito às diferenças e a tolerância (STF, 2021, online, grifo nosso).

E, ainda, no mesmo sentido, mostrando a possibilidade de restrição do direito em alguns casos, o Pacto Internacional dos Direitos Civis e Políticos prevê: 


\begin{abstract}
“ARTIGO 19. 1. ninguém poderá ser molestado por suas opiniões. 2. Toda pessoa terá direito à liberdade de expressão; esse direito incluirá a liberdade de procurar, receber e difundir informações e ideias de qualquer natureza, independentemente de considerações de fronteiras, verbalmente ou por escrito, em forma impressa ou artística, ou por qualquer outro meio de sua escolha. 3. O exercício do direito previsto no parágrafo 2 do presente artigo implicará deveres e responsabilidades especiais. Consequentemente, poderá estar sujeito a certas restrições, que devem, entretanto, ser expressamente previstas em lei e que se façam necessárias para: a) assegurar o respeito dos direitos e da reputação das demais pessoas; b) proteger a segurança nacional, a ordem, a saúde ou a moral pública"(grifo nosso).
\end{abstract}

Assim, tendo em vista os direitos em colisão (liberdade de expressão e direito à vida e à saúde) deve o poder público atuar para combater falsas notícias sobre a matéria. Tal medida encontra obstáculo na falta de previsão legislativa específica; e, algumas autoridades tem defendido a aplicação do artigo 41 da Lei das Contravenções Penais: "provocar alarma, anunciando desastre ou perigo inexistente, ou praticar qualquer ato capaz de produzir pânico ou tumulto", com pena prevista de prisão simples de 15 dias a seis meses ou multa ${ }^{9}$.

O senador Ângelo Coronel (PSD-BA) apresentou um projeto de lei, o PL 5.555/2020, que altera o Código Penal (Decreto-Lei 2.848, de 1940) tornando crime a omissão e oposição a vacinação, propagação de notícias falsas sobre a eficácia da vacina e de desestímulo à adesão ao programa de vacinação. Em consulta à página virtual do Senado, constata-se que o projeto fora retirado da pauta em 7 de Abril de 2021.

Pode-se também afirmar que este tipo de conduta de pessoas que propagam notícias falsas sobre tema tão caro ao momento fere a segurança humana. $\mathrm{O}$ conceito de segurança humana foi apresentado pela primeira vez em 1994, no informe do Programa das Nações Unidas para o Desenvolvimento (PNUD) intitulado "Nuevas Dimensiones de la Seguridad Humana", documente este que cunhou um conceito que é transdisciplinar e amplia as bases do que se conhece como Desenvolvimento Humano, Segurança e Direitos Humanos. O referido informe faz referência a sete dimensões de segurança humana, sendo um deles o da segurança da saúde.

O conceito de segurança humana e de direitos humanos estão interligados, e, segundo Amartya Sem (2000, p.1) a segurança humana pode ser considerada como uma classe de direitos humanos. A segurança humana é um conceito multidimensional, na medida

\footnotetext{
${ }^{9} \mathrm{O}$ Centro de Apoio Operacional às Promotorias do Ministério Público do Paraná elaborou o documento intitulado "Coronavírus e Reflexos Jurídico-penais - Análise das principais condutas delitivas", no qual, entre outras orientações, entende como possível a aplicação do Artigo 41 da Lei de Contravenções Penais por ocasião da propagação de fake news sobre o coronavírus, ressaltando que é necessário para a efetiva incidência desta figura delitiva que o autor tenha ciência da falsidade das informações que transmite.
} 
que se relaciona com os direitos humanos de segurança geração mas também com outros temas, tais como democracia e participação política.

Os principais documentos sobre o tema foram elaborados no âmbito da Organização das Nações Unidas e pouco se evoluiu nos últimos 20 anos a respeito de medidas práticas e aptas a concretizar o conceito. No que diz respeito à temática da saúde a Organização Panamericana de Saúde, desde 2010, tem investido em pesquisa conceitual e boas práticas sobre o tema.

Segundo a Comissão sobre Segurança Humana das Nações Unidas, em seu relatório final intitulado Segurança Humana Agora, a segurança humana significa a:

\begin{abstract}
“...protección del núcleo vital de todas las vidas humanas de forma que se mejoren las libertades humanas y la realización de las personas. La seguridad humana significa proteger las libertades fundamentales, aquellas libertades que son la esencia de la vida. Significa proteger a las personas de situaciones y amenazas críticas (graves) y más presentes (extendidas). Significa utilizar procesos que se basen en las fortalezas y aspiraciones de las personas. Significa crear sistemas políticos, sociales, medioambientales, económicos, militares y culturales que, de forma conjunta, aporten a las personas los fundamentos para la supervivencia, el sustento y la dignidad." (CSH, 2003, p. 4).
\end{abstract}

E, segundo o documento intitulado "Teoria e Prática da Segurança Humana", também produzido no âmbito das Nações Unidas, o conceito considera as epidemias como exemplo de ameaça à segurança humana sanitária.

Assim, segundo uma visão ampliada de segurança humana as epidemias constituem uma ameaça a mesma. Portanto, uma vez respeitada a multidimensionalidade de tal conceito é imperioso afirmar que segundo tais premissas é direito do ser humano se sentir seguro e livre de tais ameaças, para assim viver sem temor, sem carência e com dignidade.

Portanto, a segurança humana do ponto de vista nacional e internacional deve se estender para além das ameaças militares, e englobar também ameaças não estatais , como por exemplo, as epidemias, que afetam diretamente os indivíduos e principalmente as populações mais vulneráveis.

Neste viés, sem discutir-se aqui as diferenças conceituais entre e epidemia e pandemia, é certo que a pandemia atual constitui sério risco à segurança humana, e a disseminação de fake news sobre o assunto só tem agravado o problema.

Uma democracia digital não pode dar guarida a este tipo de comportamento, é necessário que se criem mecanismos efetivos a fim de evitar o uso indiscriminado das 
tecnologias digitais, entre elas, as redes sociais e os aplicativos de comunicação instantânea. A discussão precisa avançar a fim de que o poder público esteja apto a evitar o exercício ilimitado do direito à liberdade de expressão. Liberdade e acesso à internet não pode colocar em risco a segurança humana das pessoas.

\section{CONSIDERAÇÕES FINAIS}

A chamada democracia digital e seus mecanismos correlatos tem possibilitado às pessoas dos mais variados grupos sociais acessarem a rede mundial de computadores e assim opinarem sobre os mais variados assuntos. As tecnologias digitais levaram a cidadania a outro patamar, ampliando assim o debate público e a chamada esfera pública.

Tal grau de conectividade constitui exatamente uma das características da chamada democracia digital ou ciberdemocracia, marcada pela ampla utilização de tecnologias digitais, incluindo as redes sociais. De fato, o verdadeiro regime democrático pressupõe um ambiente de livre circulação de ideias, no qual todos tenham direito a voz. A democracia somente pode evoluir e consolidar-se num ambiente em que diferentes convicções e visões de mundo possam ser expostas, defendidas e confrontadas umas com as outras, em um debate rico e plural.

Mas, o mesmo fenômeno fez com que se propagasse o uso indiscriminado de tais canais de comunicação, fazendo com que falsas informações circulem pela internet e isso em tempos de pandemia tem colocado em risco a vida das pessoas.

Neste contexto, destacadamente virtual, o direito fundamental à liberdade de expressão não pode ser utilizado de forma absoluta e é necessário que limites sejam impostos pelo poder público a fim de coibir tais espécies de conduta. Parafraseando o Ministro Dias Toffoli o direito à manifestação do pensamento e liberdade de expressão deve ceder nos casos que impliquem perigo evidente e atual capaz de produzir males gravíssimos.

As chamadas fakes news ganharam revelância e tem provocado uma série de problemas e já existem orientações no sentido de punir tal comportamento, embora não exista ainda o tipo penal específico.

Justifica-se assim, afirmar que tal comportamento coloca em risco a segurança humana das pessoas, uma vez que uma das dimensões do conceito engloba a segurança em 
matéria de saúde e o direito do ser humano de se sentir seguro e livre de tais riscos à sua vida e integridade física.

É absolutamente normal que a engrenagem democrática se movimente e se relacione, ora com atuação de um determinado poder, ora, por outro, ora por participação pública, mas isso não implica necessariamente na utilização abusiva do direito à liberdade de expressão.

$\mathrm{Na}$ mesma linha dos ditames constitucionais, o legislador brasileiro em várias ocasiões, procedeu à ponderação entre direitos fundamentais na direção da máxima proteção aos direitos da personalidade, restringindo, em alguma medida, a liberdade de expressão. E tal ponderação deve também ser operada a fim de restringir a propagação de notícias falsas, ainda mais em matérias que envolvem o risco à saúde e à vida.

A liberdade de expressão é direito humano universal previsto no Artigo XIX da Declaração Universal dos Direitos Humanos de 1948, e pressuposto essencial ao exercício de uma cidadania ativa e também universal. Constitui-se também em direito fundamental previsto na chamada Carta Cidadã, e, como regra geral, não são admitidas restrições prévias ao exercício dessa liberdade, sendo que o Supremo Tribunal Federal tem proferido decisões traçando o alcance de tais restrições.

O desafio por ora é lutar contra a "pandemia de mentiras", bem como, identificar mecanismos aptos a coibir e punir o exercício irresponsável e desmedido do direito à liberdade de expressão no ambiente virtual. Esta luta é de todos, e está apenas começando!

\section{BIBLIOGRAFIA}

AGÊNCIA IBGE NOTÍCIAS. Internet chega a três em cada quatro domicílios do país. PNAD Contínua TIC 2017. Rio de Janeiro, 20, dez., 2018. Disponível em $<$ https://agenciadenoticias.ibge.gov.br/agencia-sala-de-imprensa/2013-agencia-denoticias/releases/23445-pnad-continua-tic-2017-internet-chega-a-tres-em-cada-quatrodomicilios-do-pais>. Acesso em: 08 set. 2019.

AGÊNCIA IBGE NOTÍCIAS. PNAD Contínua TIC 2018. Rio de Janeiro, 29, abr., 2020. Disponível em: https://agenciadenoticias.ibge.gov.br/agencia-sala-de-imprensa/2013-agenciade-noticias/releases/27515-pnad-continua-tic-2018-internet-chega-a-79-1-dos-domicilios-dopais. Acesso em: 9 jun. 2020.

ARISTÓTELES. Política. Tradução de Nestor Silveira. São Paulo: Folha de São Paulo, 2010. (Coleção Folha; v.11). 
BALLESTEROS, Jesús. Segurança humana, direitos e políticas públicas. Tradução: Alfredo de J. Flores. Revista Direito \& Justiça, Porto Alegre, v. 40, n. 1, p. 30-38, jan./jun. 2014.

BENTIVEGNA, Carlos Frederico B. Liberdade de expressão, honra, imagem e privacidade: os limites entre o lícito e o ilícito. Editora Manole, 2019.

BOBBIO, Norberto. $O$ futuro da democracia; uma defesa das regras do jogo. Tradução de Marco Aurélio Nogueira. Rio de Janeiro: Paz e Terra, 1986.

BRASIL. Pacto Internacional sobre Direitos Civis e Políticos. Brasília, DF: Presidência da República, [1992]. Disponível em: http://www.planalto.gov.br/ccivil 03/decreto/19901994/d0592.htm. Acesso em: 15 abr. 2021.

BRASIL. Supremo Tribunal Federal (2. Turma). Recurso Extraordinário 1.010.606/RJ. Liberdade de Expressão e Direito ao Esquecimento. Relator: Dias Toffoli, 11 de Fevereiro de 2021. Disponível em: http://portal.stf.jus.br/processos/detalhe.asp?incidente=5091603. Acesso em: 14 abr. de 2021.

COLNAGO, Cláudio de Oliveira Santos; JR. BRASIL, Samuel Meira. A liberdade de expressão e suas limitações: um estudo comparativo entre Brasil e Argentina., Anais. Rio de Janeiro, 2012.

DAHL, Robert A. Poliarquia: Participação e oposição. Prefácio Fernando Limongi; tradução Celso Mauro Paciornik. - I. ed. reimpr. São Paulo: Editora da Universidade de São Paulo, 2005. - (Clássicos).

FAJARDO, Vanessa. Como o analfabetismo funcional influencia a relação com as redes sociais no Brasil. BBC NEWS BRASIL, São Paulo, 12 de nov. de 2018. Disponível em <https://www.bbc.com/portuguese/brasil-46177957>. Acesso em: 07 fev. 2020.

FREITAS, Riva Sobrado de; CASTRO Matheus Felipe. Liberdade de expressão e discurso do Ódio: um exame sobre as possíveis limitações à liberdade de expressão. Revista Sequência: Estudos Jurídicos e Políticos, Florianópolis-SC, v. 34, n. 66, 2013. Disponível em: <https://periodicos.ufsc.br/index.php/sequencia/article/view/28064> Acesso em: $17 \mathrm{dez}$. 2019.

GOMES, Patrícia Oliveira; OLIVEIRA, André Soares. Os limites da liberdade de expressão: fake news como ameaça a democracia. Revista Dir. Gar. Fund., Vitória, v. 20, n.2, p. 93118, maio/agosto, 2019.

GOMES, Wilson. A democracia digital e o problema da participação civil na decisão política. Revista Fronteiras - estudos midiáticos, São Leopoldo-RS, v. VII, n³ 3 , setembro/dezembro 2005.

GOMES, Wilson. Democracia Digital: Que democracia? II Encontro da Associação Nacional de Pesquisadores em Comunicação e Política. UFMG, Belo Horizonte. Disponível em 
<https://www.researchgate.net/publication/253584902_DEMOCRACIA_DIGITAL_QUE_D EMOCRACIA> Acesso em: 28 out 2019.

GOMES, Wilson. Internet e participação política em sociedades democráticas. Disponível em <http://www.redalyc.org/articulo.oa?id=495550183008> Revista FAMECOS: mídia, cultura e tecnologia, núm. 27, agosto de 2005, pp. 58-78. Pontifícia Universidade Católica do Rio Grande do Sul, Porto Alegre, Brasil.

GURMAN, Mark. Coronavírus: Facebook, Google, Twitter e Microsoft se unem contra fake News. UOL-Universo Online, são Paulo, 2020. Disponível em: https://www.uol.com.br/tilt/noticias/bloomberg/2020/03/17/gigantes-da-tecnologia-se-unemcontra-fake-news-do-coronavirus.htm?cmpid=copiaecola. Acesso em 13 abr. 2021.

GONZÁLEZ, Maria Victória Espiñeira; CRUZ, Danilo Uzêda da. Democracia na América Latina: democratização, tensões e aprendizados. Feira de Santana: Editore Zarte, 2018.

J.A., Lindgren Alves. Direitos humanos, cidadania e globalização. Ed. Lua Nova, núm. 50, 2000, pp. 185-206. Centro de Estudos de Cultura Contemporânea; São Paulo, Brasil.

LEVISTSKY, Steven; ZIBLATT, Daniel. Tradução, Renato Aguiar. Como as Democracias Morrem. Rio de Janeiro: Zahar, 2018.

LOPES, Eduardo Lasmar Prado. Um esboço das biografias no Brasil : a liberdade de expressão, a personalidade e a constituição de 1988 / Eduardo Lasmar Prado Lopes. - São Paulo : Almedina, 2015.

MARTINS, Helena. Fake news, censura e controle na internet na era dos robôs. Agência Brasil, Brasília, 21 de dez. de $2017 . \quad$ Disponível em https://agenciabrasil.ebc.com.br/geral/noticia/2017-12/fake-news-censura-e-controle-nainternet-era-dos-robos-chega-eleicoes. Acesso em: 31 mai. 2020.

MINISTÉRIO PÚBLICO DO ESTADO DO PARANÁ. Coronavírus e Reflexos Jurídicopenais. Análise das principais condutas delitivas. Centro de Apoio Operacional das Promotorias: Criminais, do Júri e Execuções Penais. Curitiba, 2020.

MOUNK, Yascha. O povo contra a democracia: por que nossa liberdade corre perigo e como salvá-la. Tradução Cássio de Arantes Leite e Débora Landsberg. I. ed; Editora Companhia das Letras, 2019.

OLIVEIRA, Rafael Santos de; SILVA, Rosane Leal da Silva. Direitos e novas tecnologias: desafios à proteção de direitos na sociedade em rede. $1^{\text {a }}$ ed. - Curitiba: Íthala, 2017.

ORGANIZACIÓN DE LAS NACIONES UNIDAS. TEORÍA Y PRÁCTICA DE LA SEGURIDAD HUMANA: Aplicación del concepto de seguridad humana y el Fondo Fiduciario de las Naciones Unidas para la Seguridad de los Seres Humanos. Nueva York, 2009. em: https://www.iidh.ed.cr/multic/UserFiles/Biblioteca/IIDHSeguridad/12_2010/97c70a6a-82ff409c-a1de-438406607896.pdf. Acesso em: 8 abr. 2020. 
ORGANIZAÇÃO PANAMERICANA DE SAÚDE. Entenda a infodemia e a desinformação na luta contra a covid-19. Departamento de evidência e inteligência para ação em saúde. Brasília, 2020. Disponível em https://iris.paho.org/bitstream/handle/10665.2/52054/FactsheetInfodemic_por.pdf?sequence=14. Acesso em: 8, abr, 2020.

SARLET, Ingo Wolfgang. A eficácia dos direitos fundamentais: Uma teoria geral dos direitos fundamentais na perspectiva constitucional. 11. ed. rev. atual. Porto Alegre: Livraria do Advogado Editora, 2012.

SCHMITTER, P. Dangers and dilemmas of democracy. Journal of Democracy, Baltimore, v. 5, n. 2, 1994.

SEN, Amartya. Why Human Security? Presentation at the International Symposium on Human Security, Tokyo, July 2000, Disponível em: http://www.humansecuritychs.org/doc/Sen2000html. Acesso em: 7 abr. 2021.

SENADO FEDERAL. Requerimento $\mathbf{n}^{\mathbf{0}} 11$ de 2019. Brasília-DF. Disponível em <https://www25.senado.leg.br/web/atividade/materias/-/materia/137594>. Acesso em: 9 jun. 2020.

TAVARES, Wellington; ALMEIDA, Guilherme Cássio. Redes sociais virtuais e a democracia 2.0: Dinâmicas e perspectivas políticas na relação entre políticos e sociedade. Edição $n^{\circ}$ 03; Revista de Pesquisa em Políticas Públicas. Brasília, 2014.

UNITED NATIONS ORGANIZATION. Human Security Now. Comission Human Security. New York, 2003. Disponível em: https://reliefweb.int/sites/reliefweb.int/files/resources/91BAEEDBA50C6907C1256D19006A 9353-chs-security-may03.pdf. Acesso em 9 abr. 2021. 